\title{
HABLAR PARA DECIR, NO PARA MENTIR: LA LENGUA DEL MITO
}

\author{
Speaking to Say, Not to Lie: The Language of Myth
}

\begin{abstract}
Julio López Saco
julosa.ucv@gmail.com

Universidad Central de Venezuela. Universidad Católica Andrés Bello. Venezuela
\end{abstract}

Fecha de recepción: 14/10/2019

Fecha de aceptación: 15/11/2019

Resumen: El mito es un discurso narrativo, una «historia» y, en tal sentido, un logos. Se trata de un lenguaje práctico y dialógico, un acto de habla. Un lenguaje que comunica y sirve para pensar. El lenguaje mítico, oral y simbólico, es maleable, hecho que favorece multiplicidad de reinterpretaciones. Este carácter simbólico refiere un pensamiento indirecto de fuerte carga pragmática y pedagógica. Considerado lenguaje original, y catalogado como pensamiento lingüístico metafórico, a la par que lenguaje popular-materno, es un habla elegida por la historia, no definida por su letra sino por la manera en que se dice, por su intención. En este particular, el mito funciona como un metalenguaje con sentido de valor propio. Es también el mito un lenguaje emocional, que evoluciona con la naturaleza y el propio ser humano. En definitiva, es la voz colectiva, en lenguaje figurativo y metafórico, de la comunidad, a la que proporciona cohesión, identidad y un valor socio-político.

Palabras clave: mito; lenguaje; discurso narrativo; símbolo; habla original.

Abstract: The myth is a narrative discourse, a «history», and, in this sense, a logos. It is a practical and dialogical language, an act of speech. A language that communicates and serves to think. The mythical language, oral and symbolic, is malleable, fact that favors multiplicity of reinterpretations. This symbolic character refers to an indirect thought with a strong pragmatic and pedagogical charge. Considered original language, and catalogued as metaphorical linguistic thought, along with popularmaternal language, it is a language chosen by history, not defined by its letter but by the way it is said, by its intention. In this particular case, the myth functions as a meta-language with a sense of its own value. Myth is also an emotional language, which evolves with nature and the human being himself. In short, it is the collective voice, in figurative and metaphorical language, of the community, to which it provides cohesion, identity and a socio-political value.

Keywords: myth; language; narrative discourse; symbol; original speech. 
SUMARIO: 1. Introducción. 2. Mito y lenguaje. 3. Simbolizar para conocer. 4. Proto lengua original: palabra que habla diciendo. 5. Lengua natural, evocadora y metafórica. 6. ¿Conclusiones? 7. Referencias bibliográficas.

\section{INTRODUCCIÓN}

El discurso del mito, autónomo y flexible, anfibólico, subjetivo y ambiguo como ninguno, busca hablar, decir, exponer. Y lo hace a su particular modo. Desde su específica atalaya, obtiene validez como medio de conocer, y hasta de pensar. El mito posee, por consiguiente, su propio lenguaje, con su sintaxis y semántica «mítica» propia, si bien su significado se explicita en la cultura de la sociedad y su sentido en un contexto social; es, en este sentido, un juego del lenguaje, un enunciado cuyo sentido se explicita a través de claves accesibles cuando el hablante se inmiscuye en una concreta tradición histórica y cultural.

A través de tales complejos juegos se codifican aspectos de una cultura en aquellos terrenos básicos de la misma: la reproducción, la recolección, la agricultura, la caza, la jerarquía social, la guerra, etc. Cumple el papel de modelo ideal que sirve de referente y justificación de la estructura social: tanto en Grecia o Roma como en Japón y China, en Occidente y Oriente, ciudades, linajes, clanes, grupos sociales, usaron el mito como excusa de su posición preeminente, adaptándolo o modificándolo según sus necesidades particulares.

La creación mítica es una parcela abierta, un lenguaje para defender una «argumentación» comprensible por todos como base de reflexión, una potencialidad que la filosofía utilizó y criticó. El mito repta sin preocupaciones aparentes en busca de la comprensión totalizadora del mundo y, a través de su lenguaje, pleno de matices, se configura como la alternativa respecto de la lógica y la razón estructurada y adaptable para interpretar la realidad y sus cambios.

No es de extrañar, por consiguiente, que pensadores de la talla y el prestigio de Platón hubieran empleado el lenguaje mítico, adecuándolo en un modo de exposición dialogada, para conducir al lector por las veredas argumentativas que le interesaban, aunque para ello tuviese que rediseñar esos mitos o los propiciase sin más.

Discurso narrativo, historia y lenguaje pragmático son, como se verá, aspectos sustanciales del mito. En este trabajo se intentará arrojar luz acerca del lenguaje mítico en su funcionalidad simbólica, así como en su fuerza como poder evocador y metafórico, además de su prestancia como palabra y habla originaria.

\section{MITO Y LENGUAJE}

Es el mito un retazo del lenguaje, un discurso narrativo (al menos con seguridad en la Atenas del siglo v a. e. c.), y, por ende, una «historia», un logos. Se trata de un 
lenguaje práctico, dialógico, ajeno al criterio de veracidad, retórico y de fuerte carga social y política ${ }^{1}$. El mito es un lenguaje, por tanto, convertible en representación artística, que se trasmite generacionalmente de manera especialmente oral con la intención de cohesionar socialmente a una comunidad.

En sus orígenes, se podría concebir el mito como un acto de habla inserto en una sociedad de cultura oral que otorga una destacada relevancia a la memoria. El mito como discurso y porción del lenguaje se va paulatinamente desacralizando transformándose en ese devenir en narración de acontecimientos honorables de las estirpes (sagas), en leyendas con el soporte de la escritura y, en consecuencia, en literatura, específicamente en expresión poética ${ }^{2}$. Como tipo especial de lenguaje propiciará el surgimiento del lenguaje-pensamiento histórico y filosófico.

Como retazo del lenguaje el mito funciona operando en el colectivo sociopolítico de la comunidad, de la sociedad que lo escucha y lo cuenta, reteniéndolo en la memoria grupal y aprovechando sus enseñanzas para elaborar poesía, de manera que es recontado múltiples veces, incluso con añadidos o supresiones, que enriquecen sus versiones.

Si se concibe el mito como un sistema comunicativo análogo al lenguaje, un fenómeno lingüístico que informa y comunica ${ }^{3}$, se debe considerar sin ambages como un elemento de cultura, pues la cultura no deja de ser un entramado de sistemas comunicativos que adquieren la forma de discursos entrelazados entre sí. Ahora bien, el lenguaje requiere de un contexto para ser interpretable; un contexto en el que el lenguaje, mítico en este caso, permanece abierto a lecturas e interpretaciones diferentes y variables, en virtud de su carácter polifónico, ya que es producto de varias voces y está sujeto a una audición plural.

En su accionar el mito es, por consiguiente, como el lenguaje mismo, pues es dinámico, activo, simbólico, metafórico, pragmático, operativo, analógico, eminentemente más psicológico que lógico, indiferente al rígido criterio de veracidad y socio-político. Es capaz de transformarse en discurso retórico, en poesía 4 . Se trata de una variedad de discurso ideal con una doble función básica, la de hacer algo (pragmática) y la de propiciar la sociabilidad, aspectos que facilitan la cohesión de los miembros de la sociedad que cuenta sus propios mitos.

${ }^{1}$ Seguiremos en este apartado las consideraciones de López Eire y Velasco López, 2012, pp. 21-23; 25-26 y ss. También es se puede revisar al respecto, López Eire, 2002, especialmente, pp. 442.451.

2 López Eire y Velasco López, 2012, p. 29-30. Acerca de las peculiaridades de la trasmisión oral del mito, véase García Gual, 1987, pp. 27-29. Véase también, Havelock, 1986, pp. 45-67 y ss.

3 Un estudio referencial acerca del análisis del mito como lenguaje es el del eminente antropólogo francés Lévi-Strauss, 1955, en concreto, pp. 430-433.

${ }^{4}$ Burkert, 2007, pp. 31-34, para el que el mito no tiene necesidad alguna de ser creído; Caballero López, 1997, López Eire, 2004, pp. 199-200. Sobre la función político-social del mito, López Eire, 2012, pp. 56-60 y ss. 
Es el mito lenguaje para comunicar y también, por supuesto, para pensar. Paradigmático, inductivo y retórico, genera imágenes sociales colectivas que ayudan a la vida en sociedad. Como lenguaje pleno de representaciones colectivas que los miembros de una comunidad comparten, propicia una cohesión decisiva para mantener la identidad y crear cultura. Nacido de un lenguaje dialógico e interactivo, la función paradigmática y pedagógica del mito resulta innegable; como lenguaje se dirige directamente al otro, al interlocutor del que habla ${ }^{5}$. El mito, en definitiva, es una suerte de particular especie de lenguaje-pensamiento que intenta dar razón, a su modo, de los precedentes u orígenes remotos desconocidos.

\section{SIMBOLIZAR PARA CONOCER}

El mito es parte (metafórica y metonímica) inextricable del todo. Es una metáfora de múltiples significaciones y tiene una naturaleza maleable, elástica, recreativa. Se resignifica constantemente, explorando todas las posibilidades con la intención de agotar una cuestión concreta. Hace comprensible un orden consciente, en el cual existe una lógica, ofreciendo ciertas respuestas con determinadas finalidades pedagógicas y ejemplarizantes. El mito no es una producción individual, sino colectiva, en tanto que el ser humano es un ser simbólico ${ }^{6}$, un ser que interpreta datos que le suministra la realidad (así como crea mundos posibles a partir de su propia capacidad racional).

El lenguaje mítico, oral y por ende maleable, favorece múltiples reinterpretaciones $^{7}$. Es un lenguaje básicamente simbólico, de forma que su significado está

${ }^{5}$ Al respecto, Campbell, 1991, pp. 63-64.

${ }^{6}$ También es, por descontado, un ser trascendental. La toma de conciencia por el ser humano en sus primeros desarrollos prehistóricos está signada por sus preocupaciones existenciales, que el mito encauza. Interpretar el mito requerirá una comprensión por encima de un entendimiento. Ese comprender corresponde a rodear, abrazando, el saber. En tal sentido, el mito es un objeto de comprensión del universo. Comprender (en sentido afectivo e intuitivo) posibilita, qué duda cabe, interpretaciones. Implica el mito, si seguimos este razonamiento, un nivel escogido del pensamiento abstracto, en el que las imágenes son inseparables del pensamiento. Representa la forma en que la experiencia se hace consciente, revelando una verdad significativa, si bien no verificable. Se podría decir, entonces, que se trata de una verdad metafísica, así como de una forma de razonamiento que trasciende la razón, pues necesita poner en práctica la verdad que proclama. Sobre estos aspectos, resulta revelador Porrini, 2012, en especial, pp. 27-36; 44-49 y ss. Véase también Díez de Velasco, 1998, en específico, pp. 20-24 y ss. Al respecto de un empleo también alegórico del mito, sobre todo en Teágenes de Regio y Paléfato, véase García Gual, 1992, en especial, pp. 193-200.

7 Acerca de las diferentes claves lingüísticas del lenguaje mítico, es relevante Wittgenstein, 1988, 2004, p. 70 y ss., y Franch (Comp.), 1984, en concreto, pp. $41-42$ y ss. A través de la mitología las sociedades arcaicas piensan y estructuran sus códigos ético-morales y conceptos cotidianos, 
activo en el que revive el mito, el cual, por tanto, crea y recrea; esto es, presenta historias, tiene valor, encierra interpretaciones, confiere ánima a las cosas.

Como un modo específico de exponer los problemas humanos a través de prototipos, que no abarcan toda la grandeza de lo que exponen, el mito supone un lenguaje surgido de la psicología mito poética primitiva ${ }^{8}$, pleno de símbolos propios que emanan de las estructuras mentales humanas. Este carácter simbólico hace referencia a un pensamiento indirecto, no presentacional ni perceptivo directo, a una representación, debido a que el símbolo expresa aquello que carece de expresión en el ámbito de lo expresable. El símbolo como lenguaje mítico es, por lo tanto, un mecanismo de conocimiento particular: un referente de lo vivencial, lo subjetivo, un orden concreto que está más allá de los conceptos que remiten a la generalización abstracta, la objetividad y la univocidad estricta. Como discurso y modo de pensamiento peculiar, el mito y sus símbolos conducen hacia un conocimiento simbólico en el que el hombre lee y entiende un ordenamiento preestablecido en el mundo, pleno de paradojas, extrañeza y contradicciones, y capta los procesos sin hacer análisis o reflexiones conscientes ${ }^{9}$.

generando una «imagen» del mundo a través de una especie de «metalenguaje natural». Véase al respecto, Greimas, 1970, en especial, pp. 117-134; Detienne, 1985, en concreto, pp. 142-151, y López Saco, 2004, en especial, pp. 82-84. Sobre el modo subjuntivo como lenguaje propio del mito, en cuanto a posibilidad, frente al presente como realidad, pueden verse los acertados comentarios de Blumenberg, 2004, en específico, pp. 26-27, y Ortiz-Osés, 2003, pp. 25-28.

8 Para la psicología profunda los mitos funcionan como una reserva de anhelos y deseos que se expresan en «imágenes primordiales», "formas pictóricas de los instintos», "arquetipos inconscientes" a través de los cuales el inconsciente se revela a la conciencia. En este sentido, son esenciales para comprender la historia de la conciencia humana, el despertar de la misma y del yo desde el inconsciente primordial, como reflejan, de modo bastante complejo, los relatos acerca de los orígenes, de la creación del mundo y la humanidad. Sobre las imágenes psíquicas míticas es recomendable Jung, El hombre y sus símbolos, 1992, 1995, pp. 17-18 y ss., y Recuerdos, sueños, pensamientos, 1997, sobre todo, p. 39 y ss. Mientras el mito representa, desde una óptica psicoanalítica, la inconsciencia, la imaginación y el pensamiento no verbalizado, es decir, el desorden, la anarquía y el sentido, el logos es la conciencia, la razón y el pensamiento verbalizado, el orden y la funcionalidad racionalizada. La oposición, en realidad complementaria, daría preeminencia a este último, al igual que también se suele atribuir a la conciencia, como única o verdadera realidad, un tono de superioridad frente a la onírica, difícil de aceptar por su «inasibilidad» o «indemostrabilidad».

9 Los símbolos que expresan el mito son «inconscientes» universales o transculturales, reflejo del psiquismo humano y de la dimensión socio-cultural propia de la especie. La forma simbólica mítico-religiosa es, en este sentido, un mecanismo de comprensión de una realidad que está más allá de la experiencia sensorial inmediata, de un mundo dramático con poderes en conflicto. Un aspecto que, en cualquier caso, no debemos olvidar, y que es esencial en la comprensión de la dimensión mitológica, es que la conciencia mítica no distingue entre el símbolo y lo que este representa; la imagen del objeto es el objeto mismo. Para el mito no hay 
El material simbólico vinculable con lo mítico, que es parte del mundo humano de la significación y supone un producto universal transcultural de estados genéricos de conciencia, así como una simbólica personal, precede a la actividad raciocinante, y está constituido por ideas primordiales, conformándose como punto de partida para la posterior intelección, sobre la que descansan acciones que solemos denominar como "pensar». Desde este punto de vista, el ser humano debe considerarse como algo más que un animal político y social, hablador y racional, como aducía Aristóteles; debe verse también como un zoon pathetikon, un ser pasional y sensible. Los símbolos, como conjunto de imágenes contenidas en los mitos, constituyen la coimplicación de contrarios en un lenguaje mediador, lenguaje sabio y universal, de la tradición, espiritual, que no pertenece a tiempo y lugar concretos ${ }^{10}$.

El mito se conforma como un elemento del pensamiento analógico en cualquier lenguaje, formando parte de la construcción de las formas simbólicas del mismo. En tal sentido, supone un amanera antropomórfica y dramática de traducir los eventos de la naturaleza al entendimiento humano. Se diría que tiene más que ver con una cuestión de perspectivas que con una mera y simple invención. La polaridad oracional que le es propia significa su tendencia expresiva que evoluciona, simultáneamente, en afirmación y cuestionamiento, en demanda y aceptación, y en acuerdo y estilización ${ }^{11}$. Con ello se podría entender que, a su modo, "racionaliza» formas emotivas de la imaginación previas que son expresadas narrativamente.

A través del mito, el mundo se muestra con transparencia al ser humano, si bien en modo que se puede calificar de misterioso; se trata de un mundo abierto simbólicamente al que el hombre también se entrega simbólicamente ${ }^{12}$. Estos símbolos resultan de la condensación de una serie de elementos que ofrecen analogías

separación mundo real-ideal, entre existencia y significación. Véase al respecto, Cassirer, 1994, particularmente, pp. 118-120; del mismo autor, 1998, pp. 60-62 y ss.; 290-295 y ss., y Garagalza, 1990, en especial, pp. 127-128 y ss. Acerca de los mecanismos de actuación de los símbolos son excelente guías Panikkar, 1994, pp. 383-413, y Todorov, 1981, en especial, p.40 y ss.

${ }^{10}$ A través de los símbolos se evoca y se crea conocimiento, a partir de esquemas, motivos, que expresan instintos mentales que unen lo imaginario con los procesos de carácter racional. Estos "arquetipos», condensaciones de sentido vivido o vivencias esenciales del hombre, residuos semánticos de las experiencias del pasado filogenético, permiten constatar similitudes entre formaciones simbólicas diversas, alejadas espacio-temporalmente. Su trascendencia hace que pervivan bajo el umbral de la representación, en un estadio donde todo habita en conexión "creativa» y muy sutil (vid. infra). Véase al respecto, Durand, 1981, en concreto, pp. 52-53; OrtizOsés, 2001, p. 19; Sánchez Capdequí, 2005, en particular, pp. 87-88 y Corbin, 1994, en especial, pp. 14-15.

${ }^{11}$ Véase Von Hendy, 2001, en concreto, pp. 166-167, y Wheelwright, 1962, en especial, pp. 163-164 y ss. Este último acuña el vocablo «mitoide» como un estado que precede la descripción y la narrativa, fundamentado en las vías metafórica, arquetípica y confrontativa de la imaginación, y que dispone, o determina, una serie de racionalizaciones discursivas.

12 Véase Cruz Cruz, 2007, en concreto, p. 52. 
de carácter afectivo. Dichos elementos son accesos de reacción que forman tramas o complejos:

inicialmente la vida está condicionada totalmente por la afectividad, y ésta es manifestación de las virtualidades (inconscientes) instintivas; el complejo es un sistema de vías de reacción de los instintos y tendencias (de las virtualidades); estas vías están más o menos entramadas entre sí $^{13}$.

El símbolo representa y proyecta el dinamismo de un complejo, cuyo desarrollo se produce en los diversos niveles de la psique humana. En plano profundo parecieran existir tramas comunes a la humanidad (que los mitos representan), verdaderos sistemas de reacciones y asociaciones de ideas no adquiridos en el transcurso de la vida individual, sino constitutivas del subsuelo de la psiquis humana. El símbolo es una expresión que comunica un sentido, que declara un propósito significativo por mediación de la palabra. Posee una intencionalidad doble, por un lado, literal y convencional, y por el otro, apunta a cierta situación del hombre frente al mundo que le rodea.

Mientras los signos técnicos son transparentes, los simbólicos son opacos, pues el sentido patente y literal apunta analógicamente a un sentido segundo que solo se da en aquel. En el símbolo no se puede objetivar la relación analógica que une el sentido segundo al primero; únicamente viviendo en el sentido primero, y dejándose arrastrar (por estimulación interior o por solicitación asimilativa), nos podemos encontrar con el segundo sentido. Así pues, el símbolo es el movimiento del sentido primario que nos hace partícipes del sentido latente, asimilándonos a lo simbolizado, sin que seamos capaces de dominar intelectualmente la semejanza. En tal sentido, el mito es símbolo desplegado en forma de relato, articulado en un espacio-tiempo no coordinable con el de la historia crítica y erudita ${ }^{14}$.

A través de las palabras, el mito expresa la plenitud, sin disociar los ámbitos sobrenatural, natural y psíquico, de manera simbólica, sin explicar estrictamente hablando nada, pero sí descubriendo una dimensión de la experiencia. Es la expresión, no física sino simbólica, de una emoción transformada en imagen. Mientras el simbolismo lingüístico conlleva una objetivación de las impresiones sensoriales, el simbolismo mítico conduce hacia una objetivación de los sentimientos. En los actos mítico-simbólicos las emociones se concentran, condensan e intensifican, haciéndose persistentes y duraderas. En todo caso, las imágenes en las que mora el mito se conocen como una suerte de realidades debido a la identificación vivencial propia de la afectividad.

\footnotetext{
13 Cruz Cruz, 2007, p. 53.

14 Véase Ricoeur, 2004, sobre todo, pp. 250-256.
} 
Los mitos conforman, en esencia, un lenguaje capaz de expresar el ser, si bien en el nivel de la vivencia sentimental. Aunque palabra, se trata de una palabra pre objetiva y ante predicativa ${ }^{15}$. Sin embargo, no se puede dejar se indicar que, incluso para poder creer, es necesario encontrarle a la creencia ciertas «razones», formando una "teoría» que justifique dichos credos.

Las relaciones que llevamos a cabo con la experiencia aparecen mediadas por redes simbólicas que la ordenan, y que son capaces de sugerir, evocativamente, escenarios pasados susceptibles de actualizarse. Aunque el símbolo posee una expresión histórica, mostrando un perfil definitorio de una concreta sensibilidad en una época determinada, suele enfatizar el sustrato semántico que ha sido legado por la propia tradición humana, ofreciendo, en tal sentido, la posibilidad de abrir un diálogo con un pasado sin memoria del propio hombre a través de su producción imaginaria, mítico-religiosa, plena de trascendencia, y convertida en transhistórica y transcultural. Sin embargo, en nuestra modernidad, la visión se centra en los hechos desde un único enfoque ${ }^{16}$ : literalizador, capaz de estrechar o limitar posibles lecturas alternativas y reduciendo lo posible subjuntivo a lo presente indicativo. Tal mirada literal deja de lado matices propios de la mediación humana de la compleja realidad.

\section{PROTO LENGUA ORIGINAL: PALABRA QUE HABLA DICIENDO}

El mito es un habla elegida por la historia, no definida por el objeto de su mensaje (su letra), sino por el modo en que se dice (su intención), cargada de recursos semiológicos. En este particular, el mito funciona como un metalenguaje con sentido de valor propio donde la forma aparece vacía, pero presente, y el sentido aparece ausente pero pleno ${ }^{17}$. Si bien el mito es palabra, con su carácter performativo

${ }^{15}$ Cf. Cassirer, 1997, pp. 330-333 y ss.

16 Véase al respecto Coca (Edit.), 2008, en específico, pp. 66-67. El empleo del lenguaje científico, herramienta colectiva de dominio socio-político, cuenta con la existencia, no obstante, de un componente emotivo en el seno de las palabras y en las frases. La confusión entre las referencias de los enunciados y los aspectos emocionales es lo que permite al lenguaje imponer su predominio. Los científicos hablan y escriben acerca de sus logros y experimentos en un tono que quiere ser científico, pero que no deja de rezumar intuición, emoción. El uso de palabras sin sentido contiene un efecto manipulador en el marco de la política, y las definiciones preestablecidas son condicionantes en el abordaje de los temas que tratan el estudio historiográfico sobre el arte o la arqueología, mitologizando muchos de sus contenidos. Los escritos científicos tienden a presentarse a sí mismos como carentes de autor, sin sujeto implicado (que es un agente históricamente contingente), en busca de una absoluta objetividad. Sin embargo, la objetividad y la subjetividad no dejan de ser constructos en los que la imaginación juega un papel relevante. Revísese al respecto, Bermejo Barrera, 2007, pp. 6-8; y Baeten, 1996, p. 108.

17 Como un sistema semiológico el mito ni es mentira, ni una confesión, sino una inflexión interpelativa e invocativa de sentidos que pueden ser interpretados descifrando sus expresiones. 
que ofrece experiencias emocionales no percibibles en la lectura, se presenta como logos spermatikós, como discurso naciente, abierto, en oposición al discurso literario, fijo y cerrado. Entendido como una actividad noética,

el mito se injerta como un nudo de sentido y sigue una organización narrativa que no depende de la libre imaginación de su autor, de un puro juego de espíritu. Debe entonces corresponder a la mitogénesis un proceso noético específico, en el que no basta descubrir a partir de una psicología, sino que necesita, filosóficamente, de una tipología de las funciones intelectivas, de niveles de representación... ${ }^{18}$.

Como lenguaje, simbolizado como «natural-materno» por A. Ortiz-Osés, el mito ha sido estudiado, en el marco de la hermenéutica filosófica, como "madre» de la razón, portador de interpretaciones previas simbólicas sobre las cuales y, lo que es más habitual, contra las cuales, se recorta y establece el conocimiento metódico y conceptual. En su catalogación como proto-lenguaje femenino o lenguaje originario natural, implica un ámbito afectivo y discursivo que propone un relacionamiento entre las cosas y ofrece un apoyo o signo a las realidades y sus impresiones. Este arcaico lenguaje fue apropiado y desarrollado en una dirección cada vez más racionalista y abstraccionista, factor que indica que el mito se encuentra vivo como recuerdo de un lenguaje afectivo, entre los intersticios conceptuales de la cultura humana, y que el saber-logos no puede camuflar totalmente la creencia-mito. En definitiva, logos sin mythos es estéril y mythos sin logos fanatismo e ideología irracional ${ }^{19}$.

Los esquemas míticos corresponderían, de este modo, a un pensamiento lingüístico metafórico, a un lenguaje popular-materno, precedente de la separación dualística entre sentido literal y metafórico, y de la formalización posterior que convierte al lenguaje humano "paterno», en su sentido teórico más que de uso, en el de la ciencia, limitante, categorizador, artificioso y racional. El manejo conceptual, cuyo resultado es inequívoco y resistente, permite control y definición puntual sobre lo que nos rodea, pero reduce la posibilidad de aprehensión de secciones de la infinita variedad de la existencia, expresables mítica y metafóricamente. La descripción, reductora, petrificadora y organizadora, a través de un sistema representativo de términos, de un previo compositum informe y turbio, gana eficacia, pero pierde

En cuanto a sus esquemas semiológicos, véase Barthes, 1999, pp. 108-125, en especial, p. 108 y 117.

18 Véase Wunenburguer, 2002, p. 83 y 84 . El mito es poesía, oralidad, palabra, femenino, natural, salvaje, irracional, sacro y originario, frente al logos prosaico, escritura y texto fijo, masculino, cultural, doméstico, racional, profano y artificial. Puede verse, en este contexto, Bauzá, 2005, pp. 44-45, 48 y ss.

19 Cf. Ortiz-Osés, 1994, p. 225 y 229-230. Véase también Heidegger, 1990, en especial, pp. 140-141; y López Saco, 2016, pp. 105-121. 
dinamismo. El cambio de lo poético a lo prosaico reposa, entre otros factores, en una cuestión eminentemente epistemológica: el predominio de la razón sobre la intuitio irracional y analógica, tan propia de lo mítico.

Al igual que la religión, el mito emplea una lógica de carácter simbólico (vid. supra) que no es tanto explicativa como relacionadora y co-implicativa, que busca implicar, imbricar, y menos explicar o analizar; su intencionalidad, que comparte, efectivamente, con la religión, es, de este modo, coimplicar, unir los contrarios opuestos pero complementarios: bien-mal, luz-oscuridad, consciencia-transconsciencia, monstruos-héroes, en un afán ontológico de implicar holísticamente todo.

Fundido en la intuición humana del mundo fenoménico, de la realidad y del acaecer objetivo, el mito es parte integrante, por consiguiente, de la realidad humana, por eso debe ofrecérsele una interpretación existencial que permita descubrir el significado profundo que esconde. La vía mito-simbólica es útil para delatar la unidad fundamental y original de las diversas cosmovisiones, así como para despertar la conciencia humana frente al significado de la vida y el mundo.

Además del lenguaje racional, de carácter deductivo y no retórico, apodíctico, existe, por consiguiente, un lenguaje mostrativo en el que se expresan las premisas originarias del discurso racional. En este se halla inmerso el sentido común, que únicamente juzga de acuerdo a los principios representados de modo oscuro, siendo reducido a la capacidad natural, preparatoria, del ser humano que debe conducir, según los preceptos funcionalistas y racionalistas, a la desplegada, y auténtica, actividad del entendimiento. Las premisas originarias tienen carácter inderivable y no pueden ser fundamentables ni demostrables. Tal lenguaje mítico es proclamador, da noticia, pero no fundamenta, muestra y deja ver, figurativamente. Basado en imágenes, es tanto teórico como transferidor ${ }^{20}$. A tales imágenes se le transfiere, metafóricamente (expresando con ello la esencia del mundo en el que el hombre vive), un significado, comenzando así a otorgar sentido.

Este lenguaje, este discurso originario posee, entonces, un carácter predictor, no comprensible desde la racionalidad. Ese discurso originario mítico no está dentro del tiempo, sino que es, él mismo, origen y medida del proceso de explicación racional, y medida, a la vez, de su acontecer. El discurso mítico constituye un significado, actos significativos, si bien forjados en la ambigüedad y la duplicidad ${ }^{21}$. La significación mítica balancea significado y forma como dos caras de una moneda, naturalizando el concepto: para el consumidor del mito, el concepto, mitificado, es una «razón».

${ }^{20}$ Es revelador, acerca de los fundamentos originarios, Grassi, 2003, en específico, p. 31. El lenguaje mítico, como el astrológico, por ejemplo, es figurativo, operando sobre emblemas, no sobre palabras, poniendo en juego fuerzas, no vocablos. En cierto punto, podría confundirse (o asemejarse) con el pragmatismo del lenguaje de la física matemática (como la astronomía), pues en su esencia baraja también topologías.

${ }^{21}$ Al respecto de este aspecto, véase Trías, 2006, en concreto, pp. 84-95 y ss. 


\section{LENGUA NATURAL, EVOCADORA Y METAFÓRICA}

El mito posee una relación de simpatía con la naturaleza, a la que dota de mentalidad, de ánimo, con la que, inicialmente, entre en diálogo para después temerle, ejerciendo con ello un carácter modélico y evocativo, y conformándose como una sabiduría práctica. En tal sentido, es un lenguaje emocional y «filosófico», que co evoluciona con la naturaleza y con el propio ser humano ${ }^{22}$. El mito es la voz colectiva de la comunidad, viajando a través del tiempo, y cuya fuente es la naturaleza, su contenido y su sentido. Es una expresión humana del mundo en el que cada cosa posee su inteligencia, personalidad y voz propia.

En su origen el lenguaje no puede expresarse sin el mito. La lengua natural se presenta a sí misma como si fuese un relato mítico, al menos desde una óptica imaginaria. De hecho, en el momento inicial en que empieza a hablar fabula, como si por su propia naturaleza necesitase contar mitos, parábolas. Es en el orden mítico, en consecuencia, soterrado y, a menudo, reprimido y oscuro, en donde se enraíza el mundo iluminador (racional) diurno.

El lenguaje mítico, se diría en este orden de cosas, es figurativo, metafórico e inmediato, en ocasiones asociado, debido a que está al margen del enunciado científico, al ámbito literario. A través de su referida expresión simbólica se logra colmar la necesidad de unidad con la universalidad, remitiendo directamente a la superficie de lo inexpresable. Es el lenguaje de la instantaneidad y lo figurativo (carácter del eidos). En el marco del instante, de lo originario e inderivable, lo figurativo domina; esto es, la imagen o lo arquetípico ${ }^{23}$ (tanto en sentido de lo que nos afecta, týpos, como en el de que nos domina, árchonai). Mostrar y hablar, propio de las formas arcaicas del lenguaje, es un recurso figurativo, con presencia de imágenes que afectan, movilizan los ánimos. Dicho lenguaje es efectivo y retórico, a diferencia del discurso y el pensamiento racional, cuyos rasgos son otros:

22 Véase Kane, 1998, específicamente, p. 33 y 189-190, y Segovia, 2001, en especial, pp. $12-13$ y 32. El mito ofrece complejos juegos lingüísticos que codifican elementos cruciales de las culturas que perviven en el tiempo, como la caza y la recolección, la agricultura y la jerarquía social, o la guerra humana y la sexualidad. Este lenguaje facilita, sin duda, la espontánea comprensión de las cosas. Al respecto es ilustrativo Bermejo Barrera y Piedras Monroy, 1999, específicamente, p. 299.

${ }^{23}$ El mito ha sido considerado como un metalenguaje usado para hacer comprensibles las grandes cuestiones que la ciencia no ha resuelto o no ha querido resolver. Derivaría de la naturaleza emotiva del mismo mito, propia naturaleza de un ser humano, instintivamente consciente de sus limitaciones y de su naturaleza perecedera. Véase Durand, 1993, en particular, pp. 31-32. El mito como lenguaje pre semiótico está constituido por movimientos rituales, por actos, gestos de diverso tipo. Sobre esta manifestación lingüística es referencial Potamianou, 1997, sobre todo, pp. 36-37. 
Hemos distinguido dos tipos de discurso: uno, el racional, consiste en un proceso de deducción a partir de premisas «dadas»; su estructura es «mostrar» algo en relación con «razones». Ese lenguaje no es (ni puede ser) «inventivo» en el sentido originario, por lo que ha de limitarse a expresar lo que las premisas ya contienen: el «encontrar», el limitado invenire del lenguaje racional, sucede en el marco del proceso de pensamiento y en su tiempo propio y necesario, en un proceso sin «instantaneidad» ${ }^{24}$.

El mito es la tensión y el alma de las situaciones a las que el ser humano queda expuesto. Sin él, en tanto que unidad de la que se siguen situaciones con sentido, ni el pensamiento, ni las maneras de comportamiento, ni el lenguaje, podrían reconocerse en su significado humano; estarían presentes sin sentido ni objetivo.

Se ha dicho ya que el lenguaje expresivo es propio del mito. Este lenguaje posee dos elementos fundamentales, su imaginería y su fraseología. Esta diaphora denota un pensamiento simbólico en el que los vínculos conceptuales son forjados a través de metáforas innovadoras. Tal diaphora (formación de vínculos metafóricos radicales), activa una conexión, en tensión fértil, entre un vehículo, el significante, y un tenor, el significado, en el que este último (referente metafórico) posee algo vago, inarticulado, firmemente intuido, algo de consecuencias tremendas. Tal «movimiento semántico ${ }^{25}$ oculto, operaría preconscientemente, a través de elementos brutos de experiencia (cualidades, capacidades, sugestibilidades emotivamente cargadas), y sería representado unitariamente por símbolos. En este sentido, las expresiones faciales y los gestos, además de un vocabulario especializado, estarían detrás de la peculiar eficacia de la narración mítica. El mito es, sin duda, materia de palabra, pero también de lengua.

A través de la metáfora, el mito opera sobre un continuo de expresiones figurativas y literales que conforman un ciclo que va de la ficción a la ideología y viceversa, lo que explica su presencia en la cultura política y en la simbolización evocativa que supone la democracia. El mito consiste de metáforas extensas o condensadas sostenidas, que pueden ser tomadas literalmente como correctas o como las mejores expresiones para explicar hechos. A través de metáforas, como analogías condensadas, pueden los mitos llegar a articular relaciones que establezcan estructuras básicas de realidad desde las que se pueda razonar prácticamente acerca de las diversas contingencias de la existencia humana ${ }^{26}$. Las similitudes se expresan como

24 Grassi, 2003, p. 84.

25 Idea propuesta por Wheelwright, 1971, en especial, p. 159. A pesar de la argumentación mostrada, puede haber una alta dosis especulativa en esta hipótesis. Véase también, del mismo autor, 1962, sobre todo, pp. 60-82 y ss. y Schrempp y Hansen, 2002, pp. 31 y 38-39.

${ }^{26}$ Véase el excelente, y todavía plenamente vigente, trabajo de Ricoeur, 1975, en particular el Estudio IV, pp. 141-191; además es de necesaria consulta Perelman y Olbrechts-Tyteca, 1969, pp. 336-405 y ss.; y Frye, 1990, pp. 5-24, en concreto, pp. 6-7. 
identidades y esencias, con la posibilidad de reconfigurarlas para re-escribir la propia realidad.

Como las metáforas funcionan míticamente para re-articular las relaciones de significado, ejercitan una voluntad humana hacia el poder a través del reordenamiento de las relaciones políticas, pues permiten la fluidez de significados, la esencia de flujos eternos, la activa creatividad humana y la revitalización cultural. El lado metafórico y mítico de la cultura trae consigo dimensiones connotativas y analógicas de significado, que entran en juego con sus extensiones lógicas y denotativas para producir historias serias y plenas de autoridad, que llegan, o pueden llegar a ser, modélicas, impresiones duraderas, plantillas ${ }^{27}$.

Si bien los mitos, generalmente, describen, en el sentido de que son historias sobre algo, también son prescriptivos, normativos y per formativos, pues tratan sobre cómo el mundo debería ser y por qué las cosas no son de otra manera de como son. Es menester recordar que el lenguaje es solo parcialmente referencial sobre el mundo y no siempre en un modo empírico. Hay muchos juegos del lenguaje, y este se emplea de numerosas formas y maneras: puede expresar, prescribir, seducir, encarnar. Esto es paralelo a los mitos, en tanto que los mismos son sobre muchas diferentes cosas y emplean distintas clases de lenguaje y discursos. Aun aceptando la superioridad epistémica del lenguaje científico en asuntos cognitivos, el mito y el lenguaje religioso podría ser considerado un medio «superior» para aprehender las exigencias de la existencia humana ${ }^{28}$. En todo caso, tales diferencias son inconmensurables, y ninguna es más verdadera o correcta que la otra.

Un notable ejemplo de la discordia entre la expresión de pasiones naturales y la articulación del lenguaje racional se asentó en la idea del hombre silvestre, salvaje, cuya expresión se lleva a cabo a través de gestos, signos y miradas que, en todo caso, denotan la presencia y acción de un orden cósmico natural ${ }^{29}$. Esta idealización

${ }^{27}$ Véase al respecto Lincoln, 1989, sobre todo pp. 24-26 y ss., y Daniel, 1990, específicamente, p. 10 y $32-33$.

${ }^{28}$ Véase al respecto Stiver, 1996, en concreto, pp. 30-32 y ss. Si bien el mito presenta el mundo a través de una historia, un relato, y no por medio de hechos, estos no son el fin último de los asuntos, que también incluyen significados o sentidos existenciales, el mundo vivido y los orígenes primarios. En tanto que en la razón conceptual el lenguaje es un vehículo para una síntesis expansiva que representa al ser en términos de su inclusión entre otros similares por medio de una ley o clasificación, en el discurso mítico, a pesar de sus rudimentos de clasificación, el lenguaje no se reivindica como algo más allá del ser, sino que lo presenta. Es así como se entiende que en muchas cosmogonías, por ejemplo, las palabras tengan poder en sí mismas y sean sagradas. La inmediatez de la respuesta a un fenómeno singular y único implica una original correlación lenguaje-mundo, luego seccionado bajo los condicionantes de la razón conceptual en un lenguaje representacional, en el que las palabras son signos para expresar cosas. Cf. Cassirer, 1953, en especial, pp. 45-50.

29 La antropofagia prehistórica se estableció como un modelo interpretativo en la investigación. La bibliografía científica del siglo xIX, y alguna del $x \mathrm{x}$, que reclama y justifica una 
mítica implicaba un ser humano con voz, mímica y gestualidades que conformaban una oculta red de mensajes pasionales y sentimentales, emotivos, que emanaban de lo profundo de la naturaleza.

Este lenguaje pasional de los mensajes naturales, claramente mítico, se oponía al lenguaje civilizado de la razón y los conceptos abstractos, sin caer en cuenta de su complementariedad (el uno reflejo especular del otro), y dejando a un lado la necesaria relación tensional entre posibilidad y realidad:

Wir sind, wenn wir philosophieren, wie Wilde, primitive Menschen, die die Ausdrucksweise zivilisierter Menschen hören, rie MiBdeuten und nun die seltsamsten Schlüsse aus ihrer Deutung zichen ${ }^{30}$.

\section{6. ¿CONCLUSIONES?}

Es difícil, y hasta inútil, pretender concluir un trabajo que hable de mitos que, a su vez, dicen cosas. El lenguaje, en distintos modos, es usado en diferentes propósitos, y puede ser mucho más que descriptivo y empírico acerca de asuntos que pueden ser verificados o falsificados. La condición por la que «juzgamos» un mito no es el de la verificación, sino por ser significativo o por inducir sobre algo. Así, el lenguaje también puede "hacer», cambia cosas o las crea; es, o puede ser, performativo. Su uso ritual y performativo posee condiciones inherentes. La propia ficción puede ser utilizada para crear sistemas de significación y sentido en los que los humanos puedan operar social y culturalmente. Como no se tiene acceso directo a nuestra propia subjetividad, siempre existe una mediación simbólica como base de nuestro autoconocimiento; un conocimiento que es vinculado al entendimiento culturalmente dado del mundo, el resumen del cual es el mundo vital.

Para un buen número de teóricos ${ }^{31}$, incluso las palabras, conceptos y frases del lenguaje no reflejan o representan el mundo de modo directo porque no es el mun-

evolución humana ascendente, convierte el patrón interpretativo del salvaje que come seres humanos en un componente básico de la teoría. En la investigación de la prehistoria surgieron teorías que incluían el canibalismo en un esquema ético-cultural de la humanidad particular. Los ejemplos etnográficos son los que pusieron en duda el canibalismo y su paradigma. Véase PeterRöcher, 1998, pp. 32-35 y ss, y Weiss, 1987, sobre todo, pp. 140-159.

${ }^{30}$ Cf. Bartra, 1996, p. 72. "Cuando filosofamos somos como salvajes, hombres primitivos, que escuchan los modos de expresión de los hombres civilizados, los malinterpretan y después entresacan las conclusiones más extrañas de su interpretación». Véase Wittgenstein, 1988, 2004, específicamente, pp. 193-194.

${ }^{31}$ Es el caso de D. Davidson o W. v. O. Quine. Véase sobre ello, Ricoeur, 1991, pp. 117-136, y Jensen, 2009, pp. 41-43. 
do el que habla, sino el ser humano, de ahí que conciban un holismo semántico en el que los significados son inextricables del contexto.

Las sensibilidades y tendencias humanas pueden producir consecuencias sociales, puesto que producen estabilidad: la gente actúa de acuerdo a sus percepciones y elecciones, lo cual parece indicar el funcionamiento de un sentido de mutualidad

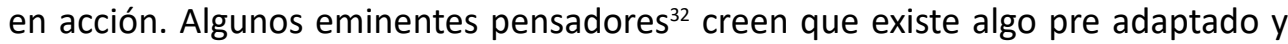
pre lingüístico que nos ayuda a alcanzar las referencias lingüísticas iniciales. El sutil y sistemático cimiento sobre el que las referencias del lenguaje descansa puede ser un reflejo de una «natural» organización de la mente, en la que el ser humano crece más a través de la experiencia vivida que del aprendizaje.

El hombre estaría, así, equipado con medios para calibrar las obras de su mente frente a otras, y para hacer lo propio con los «mundos» en los que se vive, a través de sutiles medios de referencia. Por supuesto, la referencia rara vez alcanza la puntillosidad abstracta de una expresión singular y definida, y por ello está siempre sujeta a la polisemia, y sus significados, continuamente indeterminados, presos de la ambigüedad, como es propio de la anfibología del mito.

El saber mítico expresable en su proto lenguaje originario no se parcela en disciplinas, como hace la ciencia. Es anti dogmático, un factor que lo vuelve maleable, plástico. Pervive más allá del tiempo y, transformado, es fuente de todo lo otro. Los mitos, y la mitología en general, pueden ser considerados, así sea de un modo provisional, como interpretación filosófica (entiéndase aprehensión del logos), de narraciones muchas veces sacras en las que el hombre arcaico encuentra las claves esenciales que le permiten descifrar el ente. Un proceso, a través de un lenguaje propio, necesario, por lo tanto, para la conciencia.

\section{REFERENCIAS BIBLIOGRÁFICAS}

Baeten, E. M. (1996). The Magic Mirror. Myth's Abiding Power. Albany: State University.

Barthes, R. (1999). Mitologías. Madrid: Siglo XXI.

Bartra, R. (1996). El salvaje en el espejo. Barcelona: Destino.

Bauzá, H. F. (2005). Qué es un mito. Una aproximación a la mitología clásica. Buenos Aires: F. C. E.

32 Concretamente Putnam, 1975, en especial, pp. 16-32 y ss., y Greenberg, 1963, en concreto, p. 84. 
Bermejo Barrera, J. C. y Piedras Monroy, P. A. (1999). Genealogía de la Historia. Ensayos de Historia teórica III. Madrid: Akal.

Bermejo Barrera, J. C. (2007). Moscas en una botella. Cómo dominar a la gente con palabras. Madrid: Akal.

Blumenberg, H. (2004). El mito y el concepto de realidad. Barcelona: Herder.

Burkert, W. (2007). Religión griega. Arcaica y clásica. Madrid: Abada.

Caballero López, J. A. (1997). Retórica y demagogia: el mito como instrumento de persuasión. En F. Cortés Gabaudán, G. Hinojo Andrés y A. López Eire (Comps.), Retórica, Política e Ideología desde la Antigüedad a nuestros días. Actas II Congreso Internacional de LOGO, Vol. III (pp. 49-59). Salamanca.

Campbell, J. (1991). El poder del mito. Barcelona: Emecé.

Cassirer, E. (1953). Language and Myth. Nueva York: Dover Publications.

Cassirer, E. (1994). Antropología filosófica. México D. F.: F. C. E.

Cassirer, E. (1997). El mito del estado. México, D. F.: F. C. E.

Cassirer, E. (1998). Filosofía de las formas simbólicas. Vol. II. México, D. F.: F. C. E.

Coca, J. R. (Edit.). (2008). Las posibilidades de lo imaginario. Barcelona: del Serbal.

Corbin, H. (1994). La imaginación creadora. Barcelona: Crítica.

Cruz Cruz, J. (2007). Sentido antropológico del mito. Pamplona: Universidad de Navarra.

Daniel, S. H. (1990). Myth and Modern Philosophy. Filadelfia: Temple University Press.

Detienne, M. (1985). La invención de la mitología. Barcelona: Península.

Díez de Velasco, F. (1998). Lenguajes de la Religión. Mitos, símbolos e imágenes de la Grecia Antigua. Madrid: Trotta. 
Durand, G. (1981). Las estructuras antropológicas de lo imaginario. Una introducción a la arquetipología general. Madrid: Taurus.

Durand, G. (1993). De la mitocrítica al mitoanálisis. Figuras míticas y aspectos de la obra. Barcelona: Anthropos.

Franch, J. A. (Comp.). (1984). El mito ante la antropología y la historia. Madrid: Siglo $\mathrm{XXI}$.

Frye, N. (1990). The Koine of Myth: Myth as a Universally Intelligible Language. En R. D. Denham, Myth and Metaphor: Selected Essays, 1974-1988. Charlottesville: University Press of Virginia.

Garagalza, L. (1990). La interpretación de los símbolos. Hermenéutica y lenguaje en la filosofía actual. Barcelona: Anthropos.

García Gual, C. (1987). La mitología. Interpretaciones del pensamiento mítico. Barcelona; Montesinos.

García Gual, C. (1992). Introducción a la mitología griega. Madrid: Alianza.

Grassi, E. (2003). El poder de la fantasía. Observaciones sobre la historia del pensamiento occidental. Barcelona: Anthropos.

Greenberg, J. (Edit.). (1963). Universals of Language. Cambridge: MIT Press.

Greimas, A. J. (1970). La mythologie comparée. París: Du Sens.

Havelock, E. A. (1986). The Muse learns to write: Reflections on Orality and Literacy from Antiquity to the Present. New Haven: Yale University Press.

Heidegger, M. (1990). De camino al habla. Barcelona: Serbal.

Jensen, J. S. (2009). Myths and Mythologies. A Reader. Londres: Equinox Publishing.

Jung, C. (1992, 1995). El hombre y sus símbolos. Barcelona: Caralt-Paidós-Ibérica.

Jung, C. (1997). Recuerdos, sueños, pensamientos. Madrid: Seix Barral.

Kane, S. (1998). Wisdom of the mythtellers. Letchworth: Broadview Press. 
Lévi-Strauss, C. (1955). The Structural Study of Myth. Journal of American Folklore, 68(270), pp. 428-444. https://doi.org/10.2307/536768.

Lincoln, B. (1989). Discourse and the Construction of Society: Comparative Studies on Myth, Ritual and Classification. Nueva York: Oxford University Press.

López Eire, A. (2002). El mito en la Oratoria griega. En A. López Férez (Edit.), Mitos en la Literatura Griega arcaica y clásica. Madrid: Clásicas.

López Eire, A. (2004). El mito como lenguaje. En I. G. Pinilla y S. Talavera Cuesta (edits.). Charisterion Francisco Martín García oblatum (pp. 197-214). Cuenca.

López Eire, A. y Velasco López M. (2012). La mitología griega: lenguaje de dioses y hombres. Madrid: Arco Libros.

López Saco, J. (2004). El carácter histórico-cultural del mito: aproximaciones teóricas. Presente y Pasado, 9(17), pp. 77-89.

López Saco, J. (2016). El movimiento pendular mythos-logos: hacia una dialéctica comprensiva mito-lógica. Praesentia, 17, pp. 105-121.

Ortiz-Osés, A. (1994). Hermenéutica simbólica. En K. Kerényi, E. Neumann, G. Scholem y J. Hillman (Edits.), Arquetipos y símbolos colectivos. Círculo Eranos I. Barcelona: Anthropos.

Ortiz-Osés, A. (2001). La vida simbólica. En J. D. Parra (Coord.), La Simbología. Grandes figuras de la Ciencia de los símbolos. Madrid: Montesinos.

Ortiz-Osés, A. (2003). Amor y sentido. Una hermenéutica simbólica. Barcelona: Anthropos.

Panikkar, R. (1994). Símbolo y simbolización. La diferencia simbólica. Para una lectura intercultural del símbolo. En K. Kérenyi, E. Neumann, G. Scholem y J. Hillman (Edits.), Arquetipos y símbolos colectivos. Círculo Eranos I. Barcelona: Anthropos.

Perelman, Ch. y Olbrechts-Tyteca, L. (1969). The New Rhetoric: A Treatise on Argumentation. Indiana: University of Notre Dame Press.

Peter-Röcher, H. (1998). Mythos menschenfresser. Ein Blick in die kochtöpfe der Kannibalen. Múnich: LMU. 
Porrini, S. (2012). El fulgor mítico: mito y religión en la antigua Grecia. Buenos Aires: Cantamañanas.

Potamianou, A. (1997). Faits Mythiques, Évenements Historiques, Réalite Psychique. París: Coloques de Cirisy, Mythes et Psychanalyse.

Putnam, H. (1975). Mind, Language and Reality. Cambridge: Cambridge University Press. https://doi.org/10.1017/CB09780511625251.

Ricoeur, P. (1975). La metáfora viva. Madrid: Europa.

Ricoeur, P. (1991). The Function of Fiction in Shaping Reality. En M. J. Valdes, $A$ Ricoeur Reader: Reflection and Imagination. Nueva York y Londres: Harvester \& Wheatsheaf.

Ricoeur, P. (2004). Finitud y culpabilidad. Madrid: Trotta.

Sánchez Capdequí, C. (2005). Cultura y creatividad. En A. Ortiz-Osés y P. Lanceros, Claves de Hermenéutica. Para la filosofía, la cultura y la sociedad. Bilbao: Universidad de Deusto.

Schrempp, G. y Hansen, W. (Edits.). (2002). Myth. A New Symposium. Bloomington: Indiana University Press.

Segovia, F. (2001). Invitación al mito. México, D. F.: Conaculta.

Stiver, D. (1996). The Philosophy of Religious Language: Sign, Symbol, and Story. Oxford: Blackwell.

Todorov, T. (1981). Teorías del símbolo. Caracas: Monte Ávila.

Trías, E. (2006). La Edad del Espíritu. Barcelona: Mondadori.

Von Hendy, A. (2001). The Modern construction of Myth. Indianapolis: Indiana University Press.

Weiss, G. (1987). Elementarreligionen. Eine Einführung in die Religionsethnologie. Viena y Nueva York: Springer Science. https://doi.org/10.1007/978-3-70918919-1. 
Wheelwright, Ph. (1962). Metaphor and Reality. Bloomington: Indiana University Press.

Wheelwright, Ph. (1971). The Semantic Approach to Myth. En T. A. Sebeok (Edit.), Myth: A Symposium (pp. 154-168). Bloomington: Indiana University Press.

Wittgenstein, L. (1988, 2004). Investigaciones filosóficas. Barcelona: AnthroposCrítica.

Wunenburguer, J.-J. (2002). La vie des images. Grenoble: Presses Universitaires de Grenoble. 